\title{
Sosialisasi PHBS dengan Media Komunikasi pada Siswa Madrasah Ibtidaiyah Mathla'ul Anwar Cilajim Desa Cipendeuy Kabupaten Lebak, Banten
}

\author{
Sofia Wardhani ${ }^{1}$, Vina Mahdalena ${ }^{2}$, Lusia Handayani ${ }^{2}$ \\ ${ }_{1,2}$ Universitas Pembangunan Nasional Veteran Jakarta, Indonesia
}

\begin{abstract}
A B S T R A C T
PHBS SOCIALIZATION USING COMMUNICATION MEDIA AMONG STUDENTS OF MADRASAH IBTIDAIYAH MATHLA'UL ANWAR OF CILAJIM, CIPENDEUY VILLAGE, LEBAK. One of Indonesian Government effort to increase community health status is through PHBS (Perilaku Hidup Bersih dan Sehat) campaign. RISKESDAS 2013 data showed only 34,2\% of Household in Banten practicing PHBS. There are five campaign group target, one of them are school community. We choose student of madrasah ibtidaiyah Matla'ul Andwar Cilajim desa Cipendeuy as responden because from previous observation there were a lot of student that didn't practice PHBS, in this case washing hands with soap. Method. Audio visual using video and sing with song that created by the team and practicing washing hands with soap. Conclucion. All of the first year students (30) practicing the song and washing hands with soap
\end{abstract} and end with test.

Keywords: First Year Student, PHBS, Song, Soap, Washing Hands.

\begin{tabular}{llll}
\hline Received: & Revised: & Accepted: & Available online: \\
11.10 .2019 & 11.01 .2020 & 29.01 .2020 & 14.02 .2020 \\
\hline
\end{tabular}

\section{Suggested citation:}

Wardhani, S., Mahdalena, V., \& Handayani, L. (2020). Sosialisasi PHBS dengan media komunikasi pada siswa Madrasah Ibtidaiyah Mathla'ul Anwar Cilajim Desa Cipendeuy Kabupaten Lebak, Banten. Jurnal Pengabdian Pada Masyarakat, 5(1), 157-166. https://doi.org/10.30653/002.202051.275

Open Access I URL: http://ppm.ejournal.id/index.php/pengabdian/article/view/275

${ }^{1}$ Corresponding Author: Program Studi Ilmu Gizi, FIKES Universitas Pembangunan Nasional Veteran Jakarta; Jl. RS Fatmawati No. 1, Pondok Labu, Jaksel, DKI Jakarta, Indonesia; Email: sofia_wardhani@upnvj.ac.id 


\section{PENDAHULUAN}

Kesehatan masyarakat merupakan salah satu hal utama dalam rangka kemajuan kehidupan suatu bangsa. Derajat kesehatan merupakan salah satu unsur penting dalam upaya peningkatan Indeks Pembangunan Manusia (IPM) bangsa. Perilaku masyarakat yang sadar mengenai pentingnya kesehatan dan kebersihan lingkungan merupakan hal utama yang mampu mendorong keberhasilan kemajuan kehidupan berbangsa dalam bidang kesehatan.

Kesehatan menjadi hak asasi manusia, jelas bahwa Undang-Undang Dasar Negara Republik Indonesia mendukung hal tersebut, selain UUD 45 masalah kesehatan dan kesejahteraan masuk kedalam pembahasan Sasaran Pembangunan Milenium (Millennium Development Goals atau disingkat dalam MDGs). Sehingga untuk mewujudkan hal tersebut Pemerintah Indonesia melakukan suatu dengan mensosialisasikan perilaku hidup bersih dan sehat (PHBS) kepada masyarakat. Perilaku hidup bersih dan sehat (PHBS) itu sendiri merupakan usaha individu atau kelompok dalam meningkatkan kesehatannya dengan sadar sesuai dengan pengetahuannya, sehingga mereka mampu mencegah penyakit serta memiliki andil dalam menjaga kebersihan lingkungannya hal itu tercantum dalam buku pedoman Pembinaan perilaku hidup bersih (PHBS) Kementerian Kesehatan Tahun 2011. Hasil Riset Kesehatan Dasar (Riskesdas) tahun 2013 menunjukkan proporsi rumah tangga di Provinsi Banten yang mempraktikkan perilaku hidup bersih dan sehat (PHBS) baru mencapai 34.2\%.

Upaya pemerintah melalui program PHBS ini pun kurang menunjukan hasil yang maksimal, memang nyatanya merubah perilaku seseorang tidak semudah membalikan telapak tangan. Namun upaya pemerintah melalui PHBS tidak berhenti begitu saja, program ini merupakan program yang terus berkelanjutan. Untuk menciptakan SDM yang peduli pada dunia kesehatan dan kebersihan perlu ditanamkan pengetahuan sejak dini, anak-anak merupakan SDM untuk melakukan hal itu, sehingga dapat terbiasa berperilaku hidup bersih dan sehat hingga mereka dewasa dan juga memberikan influence yang baik kepada lingkungannya.

Anak-anak usia sekolah seperti sekolah dasar (SD) merupakan anak-anak tadalah lingkungan keluarga, guru, dan juga lingkungan pertemanan. Perilaku yang ditunjukan oleh anak-anak merupakan hasil dari apa yang dilihat dan dipelajari lingkungannya. Salah satu mencegah perilaku buruk kesehatan anak adalah dengan mempraktikkan PHBS (Khumayra \& Sulisno, 2012). Berdasarkan Kementerian Kesehatan Republik Indonesia terdapat 5 Tatanan PHBS, diantaranya: PHBS di rumah tangga, PHBS di sekolah, PHBS di tempat kerja, PHBS di sarana kesehatan dan PHBS di tempat umum.

Dalam Lina (2016) menjelaskan bahwa PHBS di lingkungan sekolah mempunyai delapan indikator, yaitu mencuci tangan menggunakan air mengalir dan memakai sabun, mengkonsumsi jajanan sehat di kantin sekolah, menggunakan fasilitas jamban bersih dan sehat, melaksanakan olahraga secara teratur, memberantas jentik nyamuk di sekolah, tidak merokok di lingkungan sekolah, mengkur berat badan dan tinggi badan, serta membuang sampah pada tempat yang telah disediakan.

Namun masih saja banyak diantara sekolah-sekolah khususnya sekolah dasar (SD) di Indonesia belum mempraktikkan delapan indikator PHBS di lingkungan sekolah. Hal ini ditunjukkan dengan banyaknya data yang menampilkan bahwa sebagian besar penyakit yang sering diderita anak usia sekolah (usia 6-10) ternyata berkaitan dengan 
PHBS. Dampak lain yang terlihat ketika lingkungan sekolah belum mempraktikkan PHBS kepada siswanya adalah kurang nyamannya suasana belajar akibat lingkungan kelas yang kotor, menurunnya prestasi dan semangat belajar siswa, serta dapat membuat citra sekolah menjadi buruk, (Proverawati \& Rahmawati, 2012; Diana, Susanti, \& Irfan, 2013).

Sosialisasi harus dilakukan secara kontinyu (berkesinambungan) agar efektivitas penurunan angka penderita DBD dan diare dapat dikategorikan kecil. Kepala Dinas Kesehatan Kabupaten Lebak, HM. Sukirman menambahkan, selain konsistensi menjaga kebersihan lingkungan, masyarakat juga mulai membudayakan PHBS, serta mengonsumsi makanan yang sehat dan bergizi guna mencegah penyebaran penyakit menular tersebut. "Jika lingkungan permukiman penduduk itu bersih dan budaya PHBS dipastikan dapat meningkatkan usia harapan hidup (UHH). Kebersihan lingkungan dan PHBS juga dapat mencegah penyakit tidak menular (PTM), seperti jantung, hipertensi, stroke, dan diabetes melitus," menurut Kadinkes Lebak yang dikutip dalam Harian Kabar Banten (2018).

Sejalan dengan program pemerintah, maka kegiatan pengabdian mencuci tangan dengan sabun di sekolah Mathla'ul Anwar Cilajim ini dilaksanakan. Untuk membantu keberhasilan program maka dipilih pendekatan pembelajaran lewat media Audio dan Visual. Efektivitas media dalam pembelajaran telah terbukti dapat memberikan efek kognitif, afektif (Mahdalena, Muljono, \& Wibowo, 2019) dan konatif. Dengan demikian, media yang dirancang dan disajikan untuk pembelajaran dapat membantu anak-anak untuk memahami informasi yang disampaikan, dan menyentuh pada ranah perubahan sikap dan akhirnya dapat diwujudkan ke dalam perilaku sehari-hari.

Dari paparan analisis situasi pada bagian awal di atas maka dapat dirumuskan bahwa, siswa-siswi Madrasah Mathla'ul Anwar Cilajim merupakan aset bangsa yang perlu dilindungi dan dibina dengan baik, agar mereka terbiasa mempraktikkan PHBS demi kesehatan dan kebersihan lingkungannya. Tujuan dari kegiatan ini yaitu memberikan pengetahuan tentang PHBS kepada siswa dengan kemasan media yang menarik (presentasi visual dan lagu) sehingga tidak hanya berdampak pada ranah kognitifnya saja melainkan juga pada afektif dan perubahan perilaku (konatif).

\section{METODE}

Metode pengabdian yang dilakukan adalah pendidikan masyarakat khususnya siswa Madrasah Ibtidaiyah (MI/SD) kelas 1. Kegiatan pelatihan (praktik langsung) mencuci tangan menggunakan sabun bertujuan meningkatkan pemahaman serta kesadaran para siswa Madrasah Ibtidaiyah Mathla'ul Anwar Cilajim di Kp. Cilajim Desa Cipeundeuy Kecamatan Malimping Kabupaten Lebak, Banten.

Langkah-langkah dalam melaksanakan pengabdian masyarakat yang dilakukan, antara lain:

1) Ice breaking dilakukan di awal untuk mendekatkan diri kepada siswa dan mencairkan suasana agar tidak tegang dengan cara senam bersama selama kurang lebih 5 menit hingga siswa merasa bahwa kegiatan hari ini akan berjalan menyenangkan bukan suatu hal yang menakutkan. 
2) Brain storming mengenai cuci tangan dan dilanjutkan dengan pemaparan materi, meliputi: apa saja kegiatan PHBS, pentingnya mencuci tangan, langkah-langkah mencuci tangan menggunakan sabun, kapan kita harus mencuci tangan, dampak dari mencuci tangan menggunakan sabun, penyakit apa yang dapat dicegah ketika kita mencuci tangan. Kegiatan ini dilakukan dengan bantuan presentasi menggunakan infokus di depan kelas. Metode yang digunakan yaitu ceramah, ketua tim yang merupakan seorang dokter memberikan pengarahan kepada anak-anak bahwa mencuci tangan menggunakan sabun merupakan hal kecil namun dampaknya sangat besar bagi kesehatan.

3) Satu per satu siswa diperiksa kukunya oleh tim dibantu dengan guru kelas, jika kukunya panjang maka harus dipotong terlebih dahulu menggunakan gunting kuku.

4) Setelah dipastikan bahwa kuku mereka sudah rapi dan pendek, kegiatan selanjutnya adalah mengajak siswa untuk menyanyikan lagu cuci tangan yang telah dibuat sebelumnya oleh tim.

5) Siswa dibawa ke luar kelas untuk mempraktikkan cara mencuci tangan menggunakan sabun.

6) Evaluasi kegiatan dilakukan dengan cara tes praktik siswa (mencuci tangan dibantu dengan lagu cuci tangan)

\section{HASIL DAN PEMBAHASAN}

Kegiatan ini dilaksanakan pada tanggal 29 Juli 2019 di Madrasah Ibtidaiyah Mathla'ul Anwar Cilajim, Desa Cipeundeuy, Kab. Lebak, Banten. Siswa kelas 1 yang berjumlah 30 orang dipilih dalam kegiatan pengabdian ini. Cuci tangan diawali dengan kegiatan senam bersama selama 5 menit untuk mencairkan suasana agar anak-anak tidak tegang karena ketika tim datang dan melakukan persiapan di kelas ada beberapa anak yang ketakutan hingga menangis. Para siswa berpikir bahwa tim pelaksana pengabdian adalah petugas puskesmas yang akan memberikan vaksinasi dengan suntikan. Maka, tim berinisiatif untuk membuat suasana kelas menjadi menyenangkan dengan cara mengajak siswa untuk senam sambil sedikit berjoged dengan dipimpin oleh siswa sendiri dibantu wali kelasnya (Gambar 1).

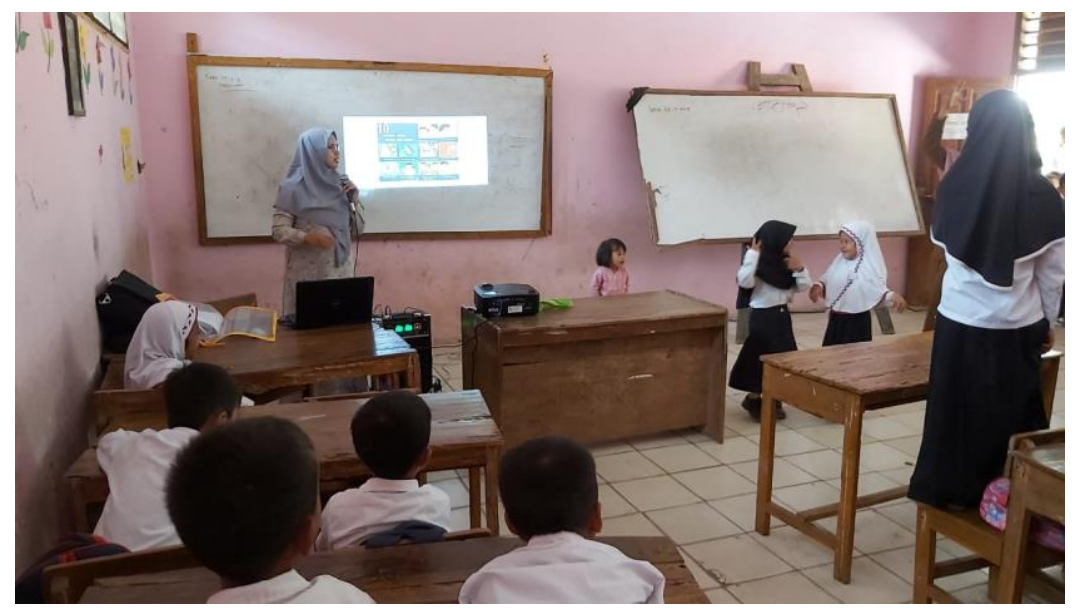




\section{Gambar 1. Suasana Pengabdian Masyarakat di MI Mathla'ul Anwar Cilajim}

Selanjutnya, brainstorming dilakukan untuk mengetahui seberapa jauh pengetahuan awal mereka tentang PHBS khususnya mencuci tangan. Beberapa mengetahui pentingnya mencuci tangan namun mereka belum bisa mempraktikkan secara benar cara mencuci tangan menggunakan sabun. Kegiatan mencuci tangan belum menjadi kebiasaan yang diterapkan sehari-hari para siswa, karena ketika ditanya apakah mereka selalu mencuci tangan sebelum makan hanya 3-4 orang yang mengangkat tangan. Kesulitan lain yang dihadapi adalah ketersediaan air di sekolah.

Tim memberikan pemaparan menggunakan presentasi media visual dengan bantuan infokus tentang materi PHBS khususnya mencuci tangan menggunakan sabun. Gerakan mencuci tangan terdiri dari 7 langkah. Dimulai dari menggosok kedua telapak tangan, lalu menggosok sela - sela jari baik dari arah punggung tangan yang diikuti dengan kedua tangan saling mengait. Setelah itu meletakkan punggung jari pada telapak tangan satunya dengan gerakan mengunci yang dilakukan secara bergantian tangan kanan dan kiri. Jempol tangan kiri digosok memutar oleh tangan kanan dan sebaliknya. Jari kiri menguncup, gosok memutar ke kanan dan kekiri pada telapak tangan kanan dan sebaliknya. Diakhiri dengan menggosok kedua pergelangan tangan. Seluruh gerakan diatas dapat dilihat pada Gambar 2.

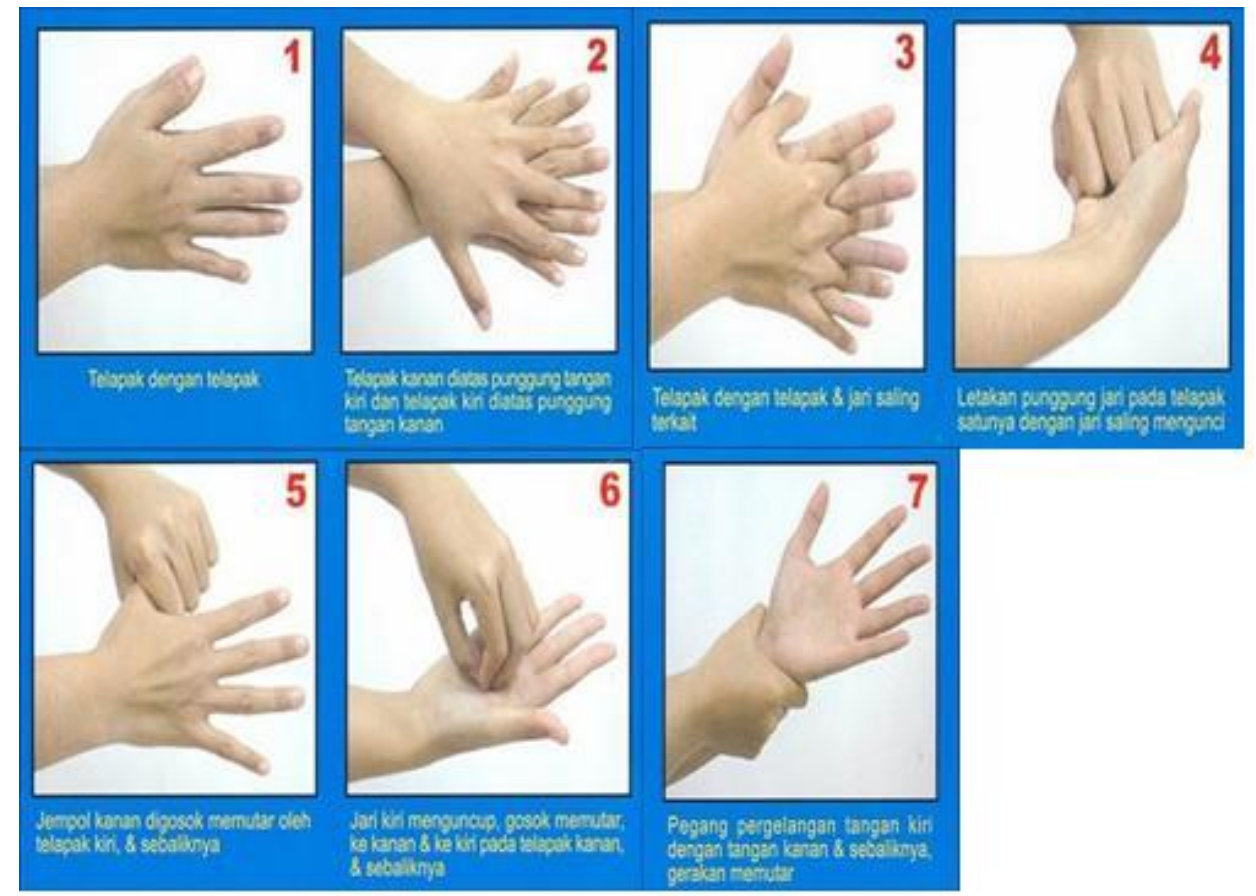

Gambar 2. Langkah-Langkah Mencuci Tangan

Setelah pemaparan materi, tim melakukan inspeksi/pemeriksaan kuku siswa. Satu per satu mereka menunjukkan kukunya, kemudian dilakukan pemotongan kuku oleh tim yang dibantu juga guru wali kelas. Sebelumnya diberitahukan bahwa seminggu sekali dilakukan pemotongan kuku oleh wali kelas biasanya dilakukan di hari Senin dan ketika pemeriksaan, ditemukan hampir seluruh kuku siswa sudah panjang dan 
hitam (Gambar 3) karena sudah seminggu lamanya sejak Senin pekan lalu (kebetulan tim datang di hari Senin).

Kuku merupakan lempengan kulit bertanduk pada permukaan dorsal ujung distal falang terminal jari tangan atau jari kaki yang tersusun dari kerak - kerak epitel yang memipih dan berkembang dari stratum lucidum kulit. Fungsi dari kuku adalah sebagai pelindung kulit dan mempertajam daya sentuh. Kuku yang memiliki kelebihan Panjang $3 \mathrm{~mm}$ dari luar ujung jari mengandung bakteri berbahaya (Infectious Disease Society of America). Penelitian yang sama juga menunjukkan kebanyakan orang tidak memcuci tangan dengan baik untuk menyingkirkan semua kuman di bawah kuku mereka. Menurut Dr. Kauffman (2013), 15 detik mencuci tangan cukup untuk menyingkirkan kuman yang kasat mata. Beberapa penyakit yang dapat disebabkan karena kuku yang panjang adalah cacingan dan diare. Cacingan banyak menyerang anak sekolah dasar karena imun tubuh yang rendah dan kebersihan individu belum cukup dilakukan oleh anak. Sementara itu diare sebagian besar $(90 \%)$ disebabkan oleh infeksi rotavirus. Sisanya dapat disebabkan oleh bakteri, parasite, jamur, keracunan makanan, alergi dan faktor psikologis. Jalur infeksi yang fecal oral merupakan jalur penularan yang dapat diputus dengan melakukan cuci tangan yang benar.

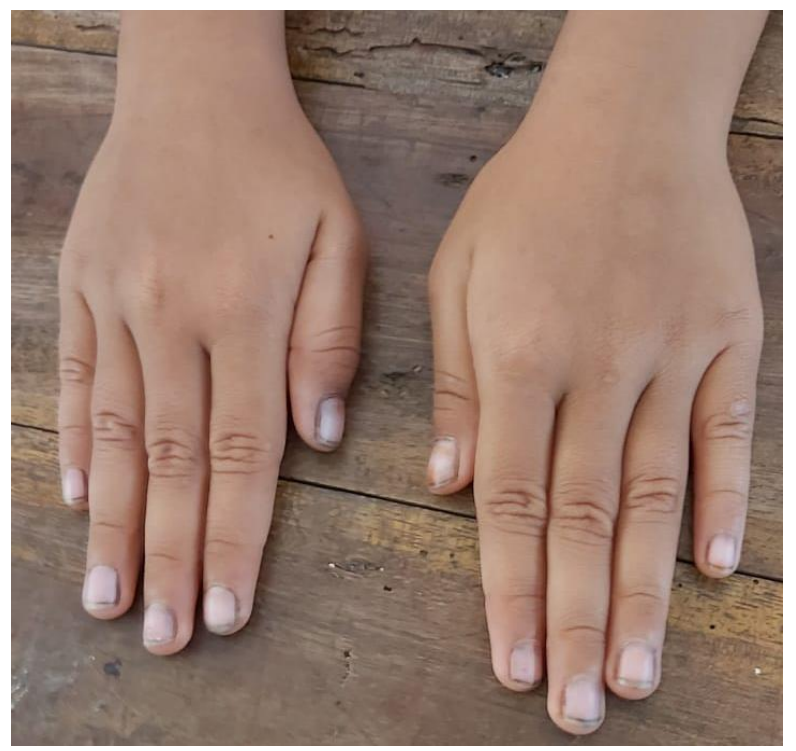

\section{Gambar 3. Pemeriksaan Kuku sebelum praktik mencuci tangan menggunakan sabun}

Setelah semua kuku siswa terpotong rapi, saatnya mempraktikkan gerakan mencuci tangan. Lagu dinilai dapat memudahkan seorang anak belajar untuk mengingat suatu hal sambil mempraktikkannya. Maka, tim berinisiatif untuk mengarang lagu dengan tema 7 langkah mencuci tangan agar anak-anak bisa menyanyikannya dengan gembira ketika mempraktikkannya.

Lirik lagu dari mencuci tangan menggunakan sabun, antara lain:

Sebelum dan sesudah melakukan tindakan

Ada 7 cara mencuci tangan

Mari, mari membersihkan tangan

Pertama, membersihkan telapak

Kedua, membersihkan punggung tangan 
Ketiga, telapak dengan telapak

Jari-jari saling terkait

Keempat, membersihkan siku jari dengan tangan saling terkunci

Kelima, membersihkan ibu jari digosok-gosok dan putar-putar

Keenam, membersihkan ujung jari

Ketujuh, membersihkan pergelangan

Itulah cara mencuci tangan, tuk menjaga kesehatan

Ketika diajak menyanyi sambil mempraktikkan langkahnya, anak-anak pun bersemangat untuk mengikuti. Lagu diulang sampai kurang lebih lima kali, agar anakanak paham dan hafal lagu tersebut. Tim pengabdian mengajari ibu guru dan memberikan rekaman lagunya untuk dihafal juga dengan harapan guru dapat meneruskan sosialisasi gerakan mencuci tangan ketika kegiatan pengabdian selesai dilaksanakan. Lagu sangat membantu dalam memberikan pengetahuan kepada anakanak karena dengan irama dan lirik sederhana mereka lebih mudah untuk mengingat dan mempraktikkannya.

Kegiatan selanjutnya, anak-anak diajak untuk berbaris dan menuju keluar kelas untuk mempraktikkan secara langsung bagaimana cara mencuci tangan menggunakan sabun yang benar (Gambar 4). Mereka dengan antusias berbaris rapi kemudian menggulung baju lengan panjangnya. Tim menyiapkan mulai dari air galon, sabun dan tissu untuk keperluan praktik. Setelah dilakukan survey sebelumnya, di sekolah tidak ada sumber air dan harus minta ke tetangga sekitar maka tim berinisiatif membawa persiapan tersebut.

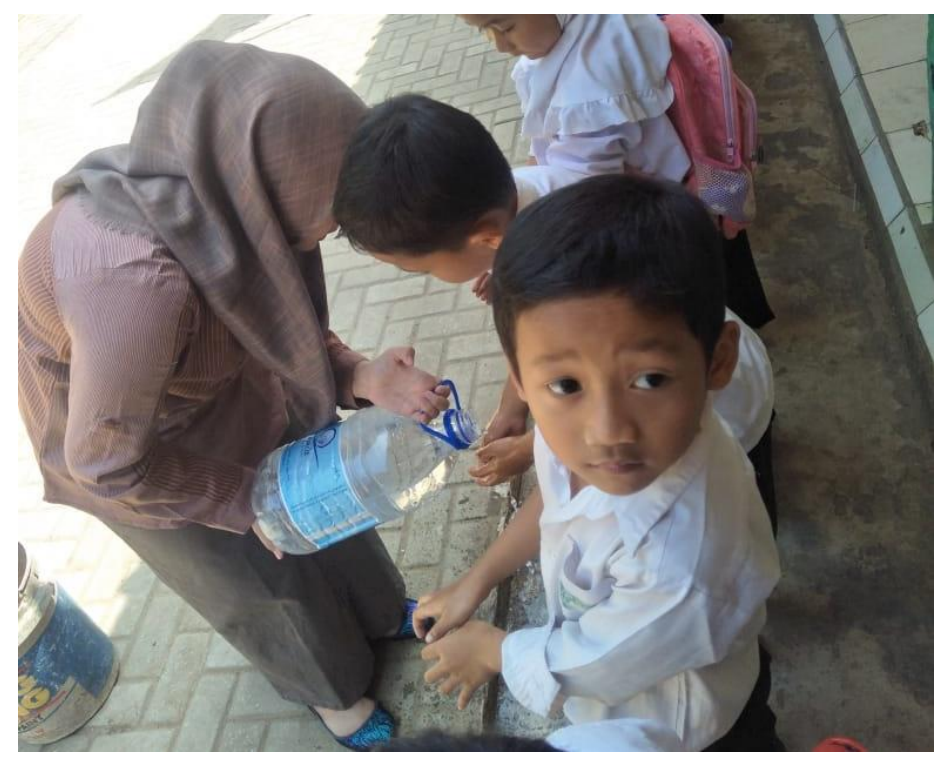

Gambar 4. Praktik Gerakan Mencuci Tangan dengan Sabun

Seluruh siswa semangat mengikuti rangkaian kegiatan hingga selesai praktik, mereka tak hentinya menyanyikan lagu agar selalu ingat apa saja langkah-langkah mencuci tangan dengan benar. Tidak mudah untuk menghafal ketujuh gerakannya namun karena lagu yang diciptakan mereka cukup cepat memahami dan menghafal bagaimana gerakannya. Kuku para siswa diperiksa kembali kuku setelah melakukan praktik cuci tangan (Gambar 5). 


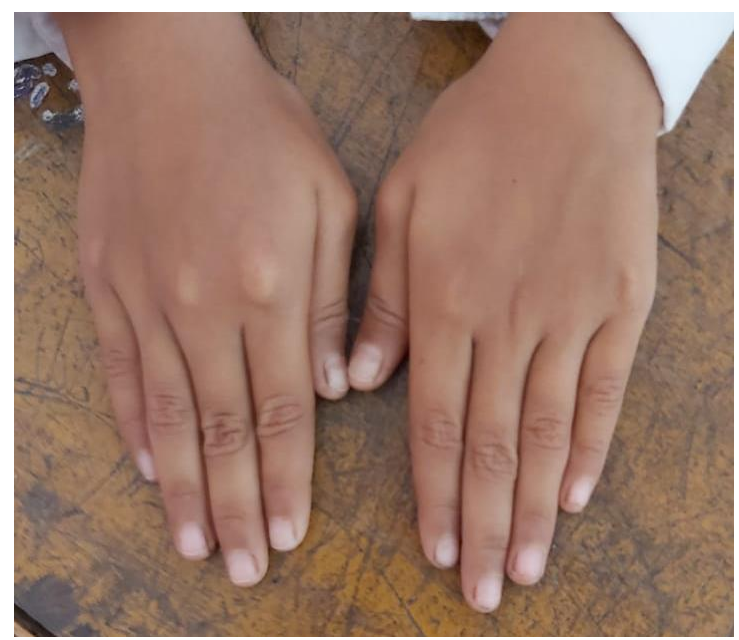

Gambar 5. Pemeriksaan Kuku setelah praktik mencuci tangan menggunakan sabun

Tangan dan kuku siswa terlihat bersih dan baunya pun wangi. Sosialisasi ini diharapkan dapat menumbuhkan kesadaran siswa bahwa dengan melakukan cuci tangan dengan benar dan menjaga agar kuku tetap pendek agar tidak ada kuman dan telur cacing yang berpotensi ada disana. Sebaut riset global (Fajriyati, 2013) menunjukkan cuci tangan pakai sabun (CTPS) mencegah kejadian diare hingga 50\% dan ISPA hingga $45 \%$.

Kegiatan terakhir yang dilakukan adalah evaluasi dengan cara mencoba siswa untuk mempraktikkan sendiri cara mencuci tangan dengan benar sambil menyanyi (Gambar 6). Para siswa sangat antusias untuk menunjukkan bahwa mereka bisa sampai tim kewalahan untuk mengaturnya karena siswa beramai-ramai maju ke depan kelas. Tim sangat senang dan bangga bahwa para siswa sudah sadar dan mampu untuk mencuci tangan sendiri dengan benar. Tidak lupa tim kembali menyanyikan lagu mencuci tangan agar siswa semakin hafal dan dapat menyebarkan pengetahuan ini ke orang lain khususnya keluarga dekat. Para siswa berjanji untuk memberitahukan pengalaman hari ini kepada keluarga di rumah.

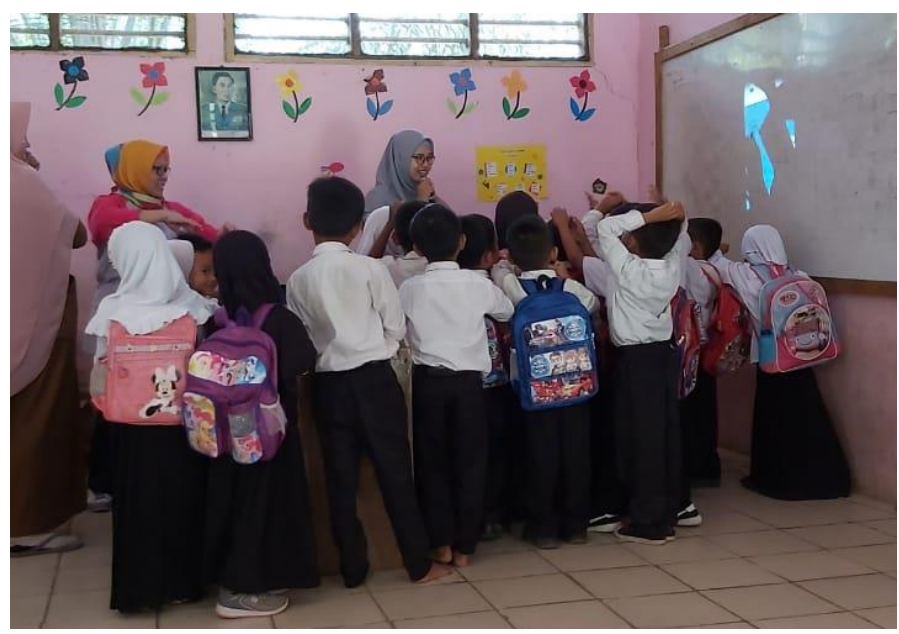

Gambar 6. Evaluasi Praktik Gerakan Mencuci Tangan 


\section{SIMPULAN}

Dari kegiatan yang dilakukan, dapat disimpulkan bahwa pentingnya sosialisasi mencuci tangan dengan sabun, dan kegiatan ini harus dilaksanakan secara terus menerus. Upaya untuk mensosialisasikan hidup bersih yang dimulai dengan mencuci tangan diharapkan dapat menjadi kebiasaan bagi masyarakat desa khususnya anakanak, sehingga terhindar dari beberapa penyakit yang berasal dari kuman kotor. Sosialisasi ini diharapkan dapat terus berlangsung, menggunakan media komunikasi seperti lagu, lebih mudah diserap anak-anak karena dirasa sangat menyenangkan, media edukasi dan entertainment bisa digunakan sebagai media sosialisasi yang sifatnya tidak sekali guna namun memiliki umur yang panjang. Pihak sekolah bisa menyimpan dan diputar atau dinyanyikan kembali sebagai pengingat (reminder) anak-anak pada momen-momen tertentu.

\section{REFERENSI}

Diana, F. M., Susanti, F., \& Irfan, A. (2013). Pelaksanaan program perilaku hidup bersih dan sehat (PHBS) di SD Negeri 001 Tanjung Balai Karimun. Jurnal Kesehatan Masyarakat Andalas, 8(1), 46-51.

Kemenkes RI. (2011). Pedoman perilaku hidup bersih dan sehat. (2011). Jakarta: Kementerian Kesehatan Republik Indonesia.

Kabar Banten. (2018). Retrieved February 10, 2019 from https://www.kabarbanten.com/dinkes-lebak-kampanyekan-kesehatan-lingkungan/

Khumayra, Z. H., \& Sulisno, M. (2012). Perbedaan pengetahuan dan sikap perilaku hidup bersih dan sehat (PHBS) antara santri putra dan santri putri. Jurnal Keperawatan Diponegoro, 1(1), 197-204.

Lina, H. P. (2016). Perilaku hidup bersih dan sehat (PHBS) siswa di SDN 42 Korong Gadang Kecamatan Kuranji Padang. Jurnal Promkes: The Indonesian Journal of Health Promotion and Health Education, 4(1), 92-103.

Mahdalena, V., Muljono, P., \& Wibowo, C. T. (2019). Pengaruh video pesan satu sisi terhadap pengetahuan dan penilaian petani pada good agricultural practices (GAP) bawang merah di Banten. Jurnal Lingkar Studi Komunikasi, 5(1), 40-54.

Maryunani, A. (2013). Perilaku hidup bersih dan sehat. Jakarta: Trans Info Media.

Proverawati, A., \& Rahmawati, E. (2012). Perilaku hidup bersih dan sehat. Yogyakarta. Nuha Medika.

\footnotetext{
Copyright and License
This is an open access article distributed under the terms of the Creative Commons

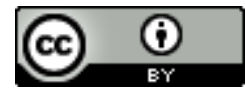
Attribution 4.0 International License, which permits unrestricted use, distribution, and reproduction in any medium, provided the original work is properly cited. (C) 2020 Sofia Wardhani, Vina Mahdalena, Lusia Handayani.
} 